\title{
Successful pregnancy and lactation outcome in a patient with Gaucher disease receiving enzyme replacement therapy -distribution and excretion of imiglucerase in human milk
}

Yoshiki Sekijima, MD, $\mathrm{PhD}^{1,2}$, Toya Ohashi MD, $\mathrm{PhD}^{3}$, Satoshi Ohira $\mathrm{MD}^{4}$, Tomoki Kosho MD, $\mathrm{PhD}^{1}$, Yoshimitsu Fukushima, MD, $\mathrm{PhD}^{1}$

${ }^{1}$ Division of Clinical and Molecular Genetics, Shinshu University Hospital, 3-1-1 Asahi, Matsumoto 390-8621, Japan.

${ }^{2}$ Department of Medicine (Neurology and Rheumatology), Shinshu University School of Medicine, 3-1-1 Asahi, Matsumoto 390-8621, Japan.

${ }^{3}$ Department of Gene Therapy, Institute of DNA Medicine, The Jikei University School of Medicine,

3-25-8 Nishishinbashi, Minatoku, Tokyo 105-8461, Japan.

${ }^{4}$ Department of Obstetrics and Gynecology, Shinshu University School of Medicine, 3-1-1 Asahi, Matsumoto 390-8621, Japan.

Correspondence: Yoshiki Sekijima, Division of Clinical and Molecular Genetics, Shinshu University Hospital, 3-1-1 Asahi, Matsumoto 390-8621, Japan.

TEL +81-263-37-2673, FAX +81-263-37-3427, E-mail sekijima@shinshu-u.ac.jp

Key words: Gaucher disease, glucocerebrosidase, enzyme replacement therapy, imiglucerase, lactation, human milk 


\section{Abstract}

Enzyme replacement therapy (ERT) with imiglucerase is a well-established, effective treatment for Gaucher disease. However, there have been no reports regarding the excretion of imiglucerase into human breast milk and its effects on the nursing infant. Here, we report a Gaucher disease patient who had successful pregnancies and lactation under ERT, and describe the distribution and excretion of imiglucerase in human milk. Following the peak of serum $\beta$-glucocerebrosidase activity, slightly increased enzymatic activity $(0.0 .16 \mathrm{nmol} / \mathrm{h} / \mathrm{mL})$ was observed in the first breast milk after imiglucerase infusion. Our data indicate that a small amount of imiglucerase is excreted into human breast milk. 


\section{Introduction}

Gaucher disease is the most prevalent glycolipid storage disorder. This disease is caused by mutations in GBA gene encoding the enzyme $\beta$-glucocerebrosidase, leading to decreased enzymatic activity and accumulation of glucocerebroside primarily within cells of mononuclear phagocyte origin, which are characteristic Gaucher cells identified in most tissues. Long-term accumulation of Gaucher cells in the liver, spleen, bone marrow, and other parenchymal organs leads to hepatosplenomegaly, anemia, thrombocytopenia, and devastating bone disease. Specific therapy for the non-neuronopathic manifestations of Gaucher disease has been available since 1991, first in the form of the macrophage targeted placenta-derived $\beta$-glucocerebrosidase (alglucerase) ${ }^{1}$ and subsequently by the recombinant human enzyme, imiglucerase ${ }^{2}$. These enzyme replacement therapies (ERT) significantly improve hematological abnormalities and hepatosplenomegaly ${ }^{1-3}$ and ameliorate skeletal complications ${ }^{4}$ in this disease.

However, there have been no reports regarding the excretion of imiglucerase into human breast milk and its effects on the nursing infant, leading to the recommendations that "caution should be exercised when imiglucerase is administered to a nursing woman" in the USA and European countries or to "stop breastfeeding during imiglucerase infusion therapy" in Japan. Here, we report a patient with type 1 Gaucher disease who had successful pregnancies and lactation under ERT, and report for the first time the distribution and excretion of imiglucerase in 
human milk.

\section{Materials and Methods}

\section{Case Summary}

The patient was a 39-year-old Japanese woman. Her clinical manifestations have been reported in part previously ${ }^{5}$. She had been well until 24 years old, when she developed general fatigue and bleeding tendency. At age 27 , she was diagnosed as having Gaucher disease based on anemia, thrombocytopenia, elevated levels of serum acid phosphatase and angiotensin-converting enzyme, hepatosplenomegaly, the presence of Gaucher cells in bone marrow aspiration, and decreased $\beta$-glucocerebrosidase activity in cultured skin fibroblasts. DNA analysis of the GBA gene for seven common mutations, c.84_85insG, c.754T>A (p.F213I), c.1226A>G (p.N370S), c.1342G>C (p.D409H), c.1448T>C (p.L444P), c.1504C>T (p.R463C), and c.1666+1G>A, showed that she was heterozygous for the c.1448T>C (p.L444P) mutation, whereas the mutation in the other allele was not identified. ERT with alglucerase (60 U/kg/2 weeks) was started immediately after the diagnosis and was later replaced with imiglucerase (60 U/kg/2 weeks). The hematological abnormalities and hepatosplenomegaly returned to normal after 6 and 24 months of treatment, respectively.

Her first pregnancy was confirmed at age 37 after 10 years of treatment with alglucerase and imiglucerase. Considering the patient's condition and recent 
publications ${ }^{6,7}$, we decided to continue ERT with imiglucerase throughout pregnancy. At 41 weeks of gestation, she had spontaneous contractions, resulting in successful vaginal delivery of a 3,121 g girl with no abnormalities (Apgar scores: 9 at $1 \mathrm{~min}$ and 10 at $5 \mathrm{~min}$ ). Given the satisfactory clinical course, we allowed maternal breastfeeding and decided to continue with imiglucerase therapy during lactation. The patient recovered well and the baby continued to have a steady and healthy development. Thirteen months after the first delivery (at age 38), she became pregnant again and ERT was continued throughout pregnancy. At 40 weeks of gestation, she delivered vaginally a normal female baby weighing 2,970g (Apgar scores: 8 at 1 min and 9 at 5 min). She restarted breastfeeding under ERT with imiglucerase. The patient remained asymptomatic during pregnancy and lactation, and the baby showed healthy development.

\section{Analysis of $\beta$-glucocerebrosidase activity in serum and breast milk}

The patient on imiglucerase therapy had her infusion discontinued 2 weeks before the study. Serum and breast milk samples were obtained before and after imiglucerase (60 U/kg) infusion for time course analysis. We also obtained breast milk samples from a nursing mother with galactorrhea as controls. The samples were stored at $-80^{\circ} \mathrm{C}$ until assay. The breast milk was centrifuged at $16000 \mathrm{~g}$ using a microcentrifuge for $10 \mathrm{~min}$ at $4^{\circ} \mathrm{C}$ and the supernatant was used as the enzyme source. Aliquots of 50 $\mu \mathrm{L}$ of serum or the supernatant of breast milk were incubated with $10 \mathrm{mmol} / \mathrm{L}$ 
4-methylumbelliferyl-beta-D-glucoside (Sigma, St. Louis, MO, USA), $0.25 \%$ sodium taurocholate, and $0.2 \%$ Triton $\mathrm{X}-100$ in $0.1 \mathrm{M} / 0.2 \mathrm{M}$ citrate-phosphate buffer for 30 $\min$ in a volume of $150 \mu \mathrm{L}$. The reaction was stopped by adding $4.85 \mathrm{~mL}$ of glycine-carbonate buffer ( $\mathrm{pH} 10.7)$ and fluorescence was read at $360 \mathrm{~nm}$ (excitation) and $448 \mathrm{~nm}$ (emission) on a spectorofluorophotometer (RF-5300PC; Shimadzu, Kyoto, Japan). The enzyme activity was expressed in $\mathrm{nmol} / \mathrm{h} / \mathrm{mL}$. This study was approved by the Ethical Committee of Shinshu University School of Medicine and informed consent was obtained from the patient and control subjects. The patient and control subjects also gave informed consent for the case report to be published.

\section{Results}

The maximum serum $\beta$-glucocerebrosidase activity $(0.119 \mathrm{nmol} / \mathrm{h} / \mathrm{mL})$ was obtained at the end of the 1-h infusion period (Figure $1 \mathrm{~A})$ as reported elsewhere (Cerezyme ${ }^{\circledR}$ package insert). Following infusion, serum enzymatic activity declined rapidly (Figure $1 \mathrm{~A})$, consistent with the short half-life of imiglucerase $\left(3.6-10.4 \mathrm{~min}\right.$; Cerezyme ${ }^{\circledR}$ package insert).

Similarly, the maximum $\beta$-glucocerebrosidase activity in breast milk $(0.016$ $\mathrm{nmol} / \mathrm{h} / \mathrm{mL})$ was obtained in the first milk after imiglucerase administration $(1 \mathrm{~h}$ after the end of infusion). However, enzymatic activity decreased to the preinfusion level ( $\leq$ $0.008 \mathrm{nmol} / \mathrm{h} / \mathrm{mL}$ ) in the subsequent samples of breast milk (Figure 1B). Breast milk $\beta$-glucocerebrosidase activity of control subjects ranged from 0.067 to 0.214 
$\mathrm{nmol} / \mathrm{h} / \mathrm{mL}$ (average $\pm \mathrm{SD}, 0.094 \pm 0.057 ;$ Figure 1B).

\section{Discussion}

ERT is a well-established, effective treatment for type 1 Gaucher disease ${ }^{1-4}$. Therapeutic goals and monitoring guidelines for treatment of type 1 Gaucher disease were outlined in 2004 and have been assisting treating physicians in the individualized management of patients with this disease ${ }^{8-10}$. However, these guidelines make no specific reference to female patients during pregnancy and lactation. There is accumulating evidence that ERT with imiglucerase before and during pregnancy could place the patient in an optimal condition to withstand the excess physiological impact of pregnancy, reduce the incidences of spontaneous abortion and complications during delivery and the postpartum period ${ }^{6,7,11,12}$. In addition, there is no evidence of adverse effects of imiglucerase on the fetus ${ }^{6,7,11,12}$. However, only one brief description of a Gaucher disease patient treated with imiglucerase during the lactation period has been published ${ }^{13}$, and no data on imiglucerase are available regarding its excretion into human breast milk and its effects on the nursing infant. Therefore, both the Food and Drug Administration (FDA) and European Medicine Evaluation Agency (EMEA) indicate that caution should be exercised when imiglucerase is administered in nursing women.

We decided to continue with imiglucerase therapy during lactation for several reasons as follows: (1) $\beta$-glucocerebrosidase is an endogenously expressed enzyme 
in infants, (2) $\beta$-glucocerebrosidase is inactivated at neutral $\mathrm{pH}$, and (3) orally ingested enzyme is likely to be digested in the gastrointestinal tract of infants. In addition, (4) imiglucerase is considered to reduce the risk of skeletal complications of the patient during lactation ${ }^{13,14}$. Under imiglucerase infusion therapy, the patient had no complications and the babies continued to show normal, healthy development during breastfeeding. Here, we presented the first report of the distribution and excretion of imiglucerase in human milk. Following the peak of serum $\beta$-glucocerebrosidase activity, increased enzymatic activity was observed in the first breast milk after imiglucerase infusion. However, $\beta$-glucocerebrosidase activity decreased rapidly to the preinfusion level in the subsequent samples of breast milk. In addition, breast milk $\beta$-glucocerebrosidase activity of the Gaucher patient was much lower than those of normal controls even in the first milk after imiglucerase infusion (Figure 1). These data indicated that a small amount of imiglucerase is excreted into human breast milk only in the first milk after imiglucerase infusion.

Breastfeeding has garnered global recognition by virtually all professional organizations as an ideal source of infant nutrition. However, decisions regarding breastfeeding may be complicated by maternal illness and/or medications. In addition to concerns about the safety of breastfeeding under ERT for nursing infant, there are concerns for the health of mothers with Gaucher disease on whom lactation imposes significant physiological demands, especially in the skeletal system, as nursing mothers transiently lose approximately $3 \%-7 \%$ of their bone density during the 
lactation period ${ }^{14}$. Mrsić et al. ${ }^{13}$ reported a Gaucher disease patient treated with imiglucerase (30 U/kg/2 weeks) who showed increased bone pain and markers of disease severity during breastfeeding. The dose of imiglucerase was increased to 60 $\mathrm{U} / \mathrm{kg} / 2$ weeks three months after the start of feeding, and the patient's general condition improved. Therefore, the decision to start and/or continue breastfeeding should be made on an individual basis by the patient's physician, considering the disease status of the patient and possible risks. ERT with sufficient dose of imiglucerase is worth being considered during breastfeeding to avoid the risk of skeletal complications.

In conclusion, a small amount of imiglucerase is excreted into human breast milk only in the first milk after infusion. A large series of patients needs to be investigated and long-term follow up of the children of those affected mothers are necessary to confirm the safety of imiglucerase infusion during lactation.

\section{Acknowledgements}

The authors thank Ms A. Mizuuchi and Drs R. Osada, T. Furukawa and Y. ligahama, T. Shiozawa for their clinical support and Ms. H. Shimizu for her assistance in $\beta$-glucocerebrosidase activity assay.

\section{Disclosure}

Dr. Yoshiki Sekijima, Satoshi Ohira, Tomoki Kosho, and Yoshimitsu Fukushima report 
no disclosures. Dr. Toya Ohashi receives research support from Genzyme Japan.

\section{References}

1. Barton NW, Brady RO, Dambrosia JM, Dibisceglie AM, Doppelt SH, Hill SC, et al. Replacement therapy for inherited enzyme deficiency--macrophage-targeted glucocerebrosidase for Gaucher's disease. N Engl J Med. 1991;324: 1464-1470.

2. Grabowski GA, Barton NW, Pastores G, Dambrosia JM, Banerjee TK, McKee MA, et al. Enzyme therapy in type 1 Gaucher disease: comparative efficacy of mannose-terminated glucocerebrosidase from natural and recombinant sources. Ann Intern Med. 1995;122: 33-39.

3. Weinreb NJ, Charrow J, Andersson HC, Kaplan P, Kolodny EH, Mistry P, et al. Effectiveness of enzyme replacement therapy in 1028 patients with type 1 Gaucher disease after 2 to 5 years of treatment: a report from the Gaucher Registry. Am J Med. 2002;113: 112-119.

4. Sims KB, Pastores GM, Weinreb NJ, Barranger J, Rosenbloom BE, Packman $\mathrm{S}$, et al. Improvement of bone disease by imiglucerase (Cerezyme) therapy in patients with skeletal manifestations of type 1 Gaucher disease: results of a 48-month longitudinal cohort study. Clin Genet. 2008;73: 430-440.

5. Yoshitama T, Nakao S, Takenaka T, Teraguchi H, Sasaki T, Kodama C, et al. Molecular genetic, biochemical, and clinical studies in three families with 
cardiac Fabry's disease. Am J Cardiol. 2001;87: 71-75.

6. Elstein D, Granovsky-Grisaru S, Rabinowitz R, Kanai R, Abrahamov A, Zimran A. Use of enzyme replacement therapy for Gaucher disease during pregnancy. Am J Obstet Gynecol. 1997;177: 1509-1512.

7. Elstein Y, Eisenberg V, Granovsky-Grisaru S, Rabinowitz R, Samueloff A, Zimran A, et al. Pregnancies in Gaucher disease: A 5-year study. Am J Obstet Gynecol. 2004;190: 435-441.

8. Pastores GM, Weinreb NJ, Aerts H, Andria G, Cox TM, Giralt M, et al. Therapeutic goals in the treatment of Gaucher disease. Semin Hematol. 2004;41: 4-14.

9. Weinreb NJ, Aggio MC, Andersson HC, Andria G, Charrow J, Clarke JT, et al. Gaucher disease type 1: revised recommendations on evaluations and monitoring for adult patients. Semin Hematol. 2004;41: 15-22.

10. Andersson HC, Charrow J, Kaplan P, Mistry P, Pastores GM, Prakash-Cheng A, et al. Individualization of long-term enzyme replacement therapy for Gaucher disease. Genet Med. 2005;7: 105-110.

11. Zimran A, Morris E, Mengel E, Kaplan P, Belmatoug N, Hughes DA, et al. The female Gaucher patient: The impact of enzyme replacement therapy around key reproductive events (menstruation, pregnancy and menopause). Blood Cells Mol Dis. 2009;43: 264-288.

12. Cox TM, Aerts JM, Belmatoug N, Cappellini MD, vom Dahl S, Goldblatt J, et al. 
Management of non-neuronopathic Gaucher disease with special reference to pregnancy, splenectomy, bisphosphonate therapy, use of biomarkers and bone disease monitoring. J Inherit Metab Dis. 2008;31: 319-336.

13. Mrsić M, Fumić K, Vrčić H, Potočki K, Štern-Padovan R, Prutki M, et al. Successful Pregnancy on Enzyme Replacement Therapy with Cerezyme. Clin Ther. 2007;29 Suppl C: S84-85.

14. Kalkwarf HJ, Specker BL. Bone mineral changes during pregnancy and lactation. Endocrine. 2002;17: 49-53. 


\section{Figure legend}

\section{Figure 1.}

Time course analysis of $(A)$ serum and $(B)$ breast milk $\beta$-glucocerebrosidase activity before and after imiglucerase (60 U/kg) infusion in the patient with Gaucher disease (open circles). Filled circles indicate breast milk $\beta$-glucocerebrosidase activity of normal controls. Imiglucerase was infused intravenously from $-1 \mathrm{~h}$ to the $0-\mathrm{h}$ time period $(\downarrow)$. 


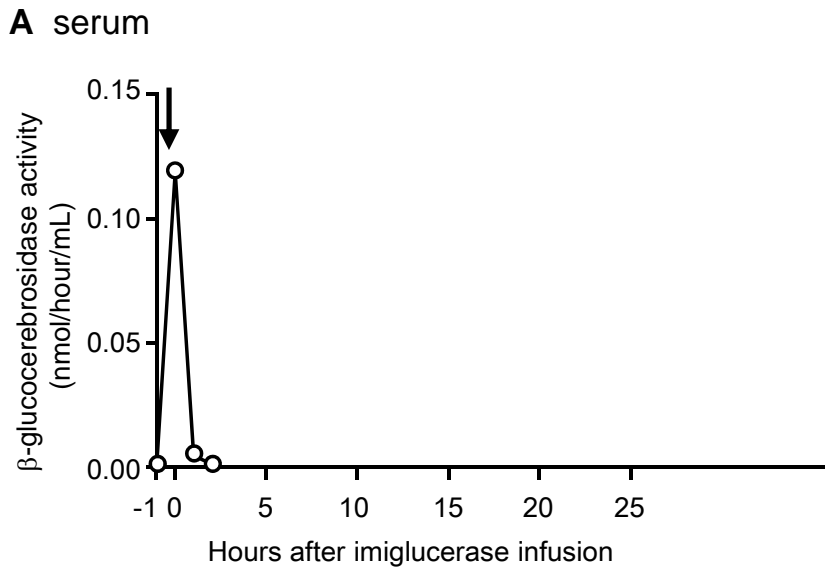

B breast milk

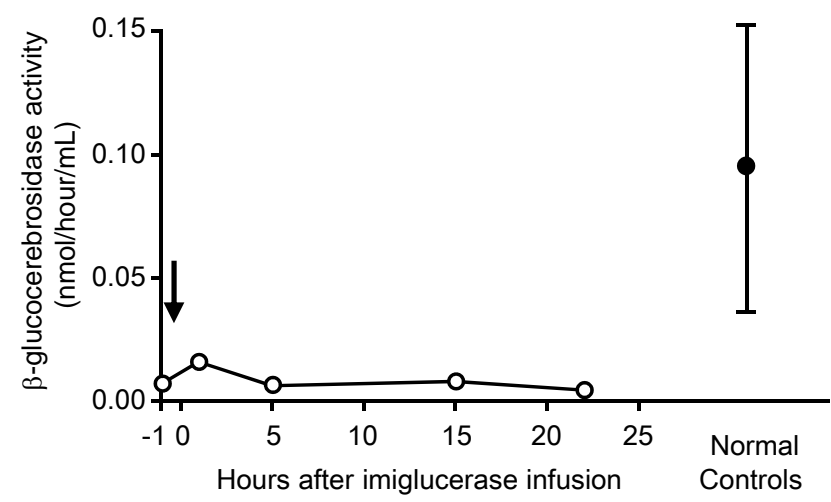

Figure 1

Sekijima et al. 